\title{
The Curiosity-Arousing Function of Anti-Drug Ads
}

\author{
Carson B. Wagner ${ }^{1, *}$ and S. Shyam Sundar ${ }^{2}$ \\ ${ }^{1}$ E.W. Scripps School of Journalism the Scripps College of Communication, Ohio University; ${ }^{2}$ Media Effects Research \\ Laboratory, Media Studies Department, College of Communications, Pennsylvania State University
}

\begin{abstract}
Anti-drug ads may be designed to prevent illicit drug use, but might they also lead to a greater desire for experimenting with drugs? Priming theory suggests the ads could cause viewers to exaggerate drug use prevalence and expose gaps in viewers' experiential knowledge. By keeping the concept of adolescent drug use salient, anti-drug ads may trigger social comparison and make them wonder why drugs are so popular. Two studies explore such a possibility. Results from an initial between-participants experiment $(\underline{N}=65)$ indicate curiosity-arousal may be an unintended function of viewing anti-drug ads. A follow-up study $(\underline{N}=28)$ replicates the findings and further examines likely causes of curiosityarousal.
\end{abstract}

\section{INTRODUCTION}

Research has shown that anti-drug ads are enormously successful in reaching target audiences (Reis, Duggan, Adger, \& DeAngelis, 1994), getting their attention (Black, 1991), and changing their attitudes to be more anti-drug (Davis, 1997). Yet, we have not witnessed a substantial decrease in drug use recently, despite a federal provision of $\$ 195$ million per year for the purchase of commercial space across various media (Kane, 1998). In fact, we have unfortunately seen illicit drug use rates among youth rise in recent years (Johnston, O'Malley, \& Bachman, 2003). Although prior research has shown that various types of viewers, such as those who are rebellious (Skinner \& Slater, 1995), may not be affected by or may even distrust anti-drug ads, most studies show a positive relationship between ad exposure and anti-drug attitudes.

Examined together, the evidence is quite puzzling, because it indicates that drug use should be in sharp decline. However, it is not, and these seemingly contradictory data have inspired the present line of research seeking to uncover unintended effects of prosocial media messages. In particular, we wonder whether anti-drug PSAs somehow trigger cognitions that might influence behavior in an undesirable direction. Perhaps by looking past the anti-drug attitudes traditionally studied in PSA research, we may get a clearer picture of how anti-drug ads function by studying cognitive responses that could potentially influence people to experiment with drugs.

Two concepts from social cognition are particularly relevant: priming and curiosity. First, priming effects theory posits that stimulus elements in media messages are capable of evoking semantically-related thoughts among viewers, and research has shown that televised depictions of various behaviors can lead to an exaggerated sense of the behavior's prevalence in society (Berkowitz, 1984). Iyengar, Peters, and Kinder (1982) extended the definition of priming, claim-

*Address correspondence to this author at the: Scripps School of Journalism at the Scripps College of Communication, Ohio University, USA; Tel: (740) 593-9808; Fax: (740) 593-2592; E-mail: wagnerc1@ohio.edu ing that media prime audiences by making certain issues more salient than others. Their studies have demonstrated that mass-mediated suggestions about a given topic raise the level of importance one places on that issue.

The second concept, curiosity, has been established as a crucial motivational force in influencing human behavior (Lowenstein, 1994). It has been shown that curiosity can increase brand recognition (Fazio, Herr, \& Powell, 1992) and that it can also prompt experimentation with drugs and alcohol (Green, 1990). Lowenstein's (1994) information-gap perspective on curiosity explains such phenomena by positing that encounters with such "mysterious" stimuli as drugs and advertising may induce cognitive "deprivation that arises from the perception of a gap in knowledge or understanding."

From this perspective, it could be argued that anti-drug ads evoke drug-related curiosity, thus undermining their prosocial effects. We conducted two controlled experiments to test such a possibility. This article will first provide a brief review of prior anti-drug ad research-along with a more indepth analysis of the concepts of priming and curiosity-and then describe the studies. The article concludes with a discussion of the findings.

\section{Prior Anti-Drug Ad Research}

The bulk of research on the effects of anti-drug messages concentrates on awareness, knowledge, attitudes, affect, and behavioral intent (see, e.g., Atkin, 2001; Atkin \& Freimuth, 2001; Paisley, 2001; Palmgreen, Lorch, Donohew, \& Harrington, 1995; Salmon \& Murray-Johnson, 2001; Wartella \& Middlestadt, 1991), with studies often investigating the manner in which variations in content, form, and argumentation style evoke changes in dependent variables of interest (McGuire, 2001). Beyond manipulating media variables, individual differences among viewers have also been widely examined (Petty, Baker, \& Gleicher, 1991). For example, it has been shown that people whose values parallel those advocated in a commercial tend to believe those ads that contain statistical evidence about the harmful effects of drugs, but people who oppose such values trust ads that include 
anecdotes about drug experiences (Slater \& Rouner, 1996). Rebellious youth have been shown to distrust anti-drug ads altogether (Skinner \& Slater, 1995). When testing both PSA type and audience traits, individual differences tend to moderate PSA effects. Studies dedicated to the effects of ads on sensation seekers have included variations in message sensation value (Palmgreen, Donohew, Lorch, Rogus, Helm, \& Grant, 1991), style and form sensation values (Everett \& Palmgreen, 1995), and program context (Lorch, et al., 1994), and these studies have shown that: a) more sensational messages and styles better increase drug awareness and anti-drug attitudes of sensation seekers as opposed to non-sensation seekers; and b) the ads' efficacy among the target audience increases as the context becomes more sensational.

Broader survey research has demonstrated that, along with sensation-seeking, gender, education, and prior experience (first- and second-hand) also determine adolescents' judgments of risk judgments regarding alcohol (Slater \& Rasinski, 2005). Studies have also shown a negative correlation between age of initial use and probability of drug and alcohol abuse at a later time (DeWit, Offord, \& Wong, 1997; Hawkins, Graham, Maguin, Abbott, Hill, \& Catalano, 1997). While many teens may experiment with drugs and alcohol, their use often declines during their twenties (Chen \& Kandel, 1995; DeWit, Offord, \& Wong, 1997), and this appears to happen in connection with the increased responsibility and roles of adulthood (Bachman, Wadsworth, O'Malley, Johnston, \& Schulenberg, 1997).

In general, anti-drug commercials can increase anti-drug attitudes among adolescents (e.g., Kelly \& Edwards, 1992; Reis, Duggan, Adger, \& DeAngelis, 1994), and survey research has shown that the ads can also prompt adolescents to take action by calling an anti-drug hotline (Palmgreen \& Donohew, 1994). Prior research has investigated attitude efficacy across "various source, message, recipient, and channel variables" (Baker, Petty, \& Gleicher, 1991, p. 200), and it has demonstrated that the commercials work best when they are targeted toward specific audiences (Donohew, Lorch, \& Palmgreen, 1991; Kelder, Pechmann, Slater, Worden, \& Levitt, 2002). Over time, researchers have identified particular independent variable combinations that increase the ads' ability to affect attitude formation and change (Atkin, 2001; McGuire, 2001).

\section{Social Cognition and Anti-drug PSAs}

Despite focusing on attitude change, the underlying aim of anti-drug ads is most often behavioral change (Atkin \& Freimuth, 2001). But, attitudes are not always the best predictor of future behaviors (Fazio, 1990; Fazio \& TowlesSchwen, 1999), especially when the behaviors are sociallysensitive such as drug use (Carifio, 1994; Carifio \& Biron, 1978; Dovidio \& Fazio, 1991). Moreover, such behaviors may oftentimes be decided upon less deliberately or rationally than one might hope (Dovidio \& Fazio, 1991; Fazio, 1990), which highlights a need for measuring drug ad effects that may be less easily controlled. To that end, this section introduces new research investigating PSA effects through two theories of social cognition - priming effects theory and the information-gap perspective on curiosity. This exploratory research departs from most prior research in that it does not vary PSA type or audience traits, but rather it investigates the effects of presence or absence of the ads on drugrelated curiosity in the context of the surrounding social environment.

\section{Priming Effects Theory}

Perhaps the most fundamental theory that might predict unintended effects of anti-drug ads is priming effects theory, wherein stimuli are thought to activate thoughts about a specific topic by providing examples that make it more "available" to viewers (Berkowitz, 1984). The more easily examples come to mind, in turn, the more a person will judge the event to happen frequently. For example, if a viewer watches a movie or a news program containing stories about illicit drug use, he or she will start to imagine that the activity is more common because examples stored in memory as well as those imparted by the stimulus are available. As such, priming participants with mass-mediated depictions of various behaviors can cause an exaggerated sense of the behaviors' prevalence in society. Iyengar, Peters, and Kinder (1982) have also examined priming effects in agenda-setting, and they showed that by focusing on certain issues and ignoring others, news media can alter the way we evaluate political figures by making some issues more salient than others.

As media stimuli, anti-drug ads may also prime viewers by making drug-related thoughts more available. Based on priming theory and research, this should lead them to cognitively exaggerate the prevalence of drug use in society:

H1: Participants exposed to anti-drug ads will estimate the prevalence of drug use among their peers to be significantly higher than participants who are not exposed to the PSAs.

\section{The Information-gap Perspective on Curiosity}

The information-gap perspective, proposed by Lowenstein (1994) and built on prior theory and research, posits that curiosity arises when one perceives a gap in her or his knowledge of a particular subject, either when the gap, itself, becomes apparent, or when the entire set of knowledge becomes evident wherein a disparity exists. The "information gap" is represented by an incongruity between "what one knows and what one wishes to know." Lowenstein predicts that many circumstances can provoke the perception of an information gap, including instances wherein one suspects that those in social proximity possess certain information that one does not. For example, if one believes that peers are privy to the definitions of various drug-related terminology such as "shotgun," "jonesing," "dugout," or "k-hole," he or she will become curious to know what those words mean.

Literature on perception of norms, which refers to beliefs about social standards, supports such a position in that normative influence-believing something is commonly done or socially acceptable-leads people to conform to the standards they perceive (Cialdini, Reno, \& Kallgren, 1990). Further, both curiosity and normative influence only come to bear on present action when made salient. One facet of perception of norms research focuses on the injunctive meaning of norms, which refers to morally approved and disapproved conduct, and which covers those behaviors one feels they 
ought to do or at least know about (Cialdini, Reno, \& Kallgren, 1990). This might also be described as "social comparison," typically known as "keeping up with the Joneses," which refers to the psychological process wherein one uses those in her or his social group as referents for what he or she should know, how he or she should act, and what he or she should possess (Myers, 1987, p. 344).

Perception of norms literature also describes what are called descriptive norms. "Descriptive norms" refers to the idea that various behaviors appear practical when numerous people are engaged in them. In other words, descriptive norms are functioning when one says "if everyone is doing it, then it must be a sensible thing to do" (Cialdini, Reno, \& Kallgren, 1990). For example, when one examines the latest election polls to determine for which candidate to vote, that person could be assuming that if the majority of people are supporting a particular candidate, that candidate must be a reasonable choice.

Perception of norms and social comparison refer to phenomena that may be underlying causes of curiosity. Lowenstein's (1994) assertion that curiosity is evoked when one imagines that others are more informed about a topic than oneself may have its roots in these processes, as they might likely cause one to become interested in conforming to a common behavior. This, in turn, should make her or him curious about that behavior.

As priming effects theory states that media stimuli work to increase one's estimation of a behavior's social prevalence and make an issue salient, if anti-drug ads prime audiences to imagine that more people use drugs, then the spots may activate curiosity through perception of norms and social comparison:

H2: Participants exposed to anti-drug PSAs will express greater curiosity about illicit drugs as compared to participants not exposed to PSAs.

Further, the information-gap perspective holds that curiosity is triggered by an increased salience of the gap in information between the beholder and her or his peers. Based on the idea that priming will evoke the notion that others possess more knowledge about a subject:

H3: Regardless of exposure to PSAs, participants' estimates of drug use prevalence will predict their level of curiosity about illicit drugs.

\section{MATERIALS AND METHODOLOGY: STUDY 1}

All participants $(N=65)$ in a two-condition betweenparticipants experiment saw a primetime television program with a large adolescent demographic (The Simpsons). A control group saw an unaltered version of the program. An experimental group saw the same program with three 30second and one 15-second anti-drug ads edited into the commercial breaks. After exposure to the program, drugrelated responses were measured.

\section{Participants}

Sixty-five high school seniors participated in the study, with thirty-six of them exposed to the experimental treatment. All participants were enrolled in an introductory psy- chology class offered exclusively to seniors, and their participation introduced them to social science experimental research methods.

All participants below the age of eighteen received parental consent for their involvement via parental consent forms distributed two weeks prior to the experiment. The parental consent forms were sealed in envelopes also containing return envelopes and sent home with students. Parents were asked to seal the consent forms in the return envelopes and return them to school. Students eighteen or older, as well as those who received parental consent, indicated their consent to participate in the study via forms that did not disclose the purpose of the study.

\section{Procedure}

Participants were told at the time of recruitment that they would be participating in research exposing them to social science experimental procedures and were tested at the regularly-scheduled Psychology classroom. Three classes participated in the study. One was randomly assigned to the experimental condition while the other two were assigned to the control condition. One male researcher administered the study.

The class instructor introduced the researcher to the class before the experiment began. The researcher then introduced himself and described and distributed consent forms to the students. After collecting the forms, the researcher explained the experimental procedure and presented the stimulus material to participants on a 27 -inch television placed at the front of the class. The experimenter then explained the procedure for filling out and returning questionnaires and distributed the measures to participants. After all participants had completed the questionnaires, the experimenter collected them and fielded any questions participants had about the procedure. Participants were then thanked for their participation, asked to refrain from discussing the procedure with others until after school, and dismissed.

\section{Stimulus}

An episode of The Simpsons entitled "Simpsoncalifragilisticexpiala(annoyed grunt)cious" was used in order to avoid participants recalling the particular program. This episode parodies the classic Disney film Mary Poppins, a musical about a magic nanny.

\section{Experimental Conditions}

The control group was shown the episode as it originally aired, complete with commercials. Four current anti-drug ads obtained from the Partnership for a Drug-Free America (PDFA) were added into the normal commercial breaks of the experimental condition stimulus. The PSAs were demographically-targeted to teens as prescribed by PDFA, and they were deemed appropriate for the sample's socioeconomic background by the researchers. Further, the ads used were chosen to incorporate a range of PSA types including emotional and rational appeals as well as physical and social threat fear appeals. Three of the PSAs were thirty second spots, and the fourth lasted fifteen seconds. (see Appendix A for descriptions in order of presentation). 


\section{Dependent Measures}

Questions assessing perceptions of social norms required participants to estimate the percentage of high school students who have used marijuana in the past year and the past month, along with the percentage who are daily marijuana users. In addition the questionnaire contained a battery of twenty-six drug-related statements designed to gauge participants' curiosity toward drug use. A majority of the drugrelated statements were based on items from the Substance Abuse Attitude Survey maintained at Rutgers University (see Chappel, Veach, \& Krug, 1985). Each item included a Likert scale wherein participants indicated their agreement with the statements by circling letters representing "very much disagree," "somewhat disagree," "undecided," "somewhat agree," and "very much agree." (see Appendix B for a copy of the questionnaire).

\section{Data Analysis}

Each of the three perception-of-norms items were entered as dependent variables in three separate one-tailed $t$-tests in order to test H1. Responses to the twenty-six drug-related Likert scale measures were subjected to a factor analysis, and those measures loading under each resulting factor were then summed, with equal weighting, to form an index. The indices obtained in this manner were checked for internal consistency before being entered as dependent variables in inferential statistical tests pertaining to $\mathrm{H} 2$. The third hypothesis was tested by regressing participants' level of curiosity upon their estimates of prevalence of drug use among high school students.

\section{RESULTS}

A factor analysis yielded six factors with eigenvalues greater than one. Six common factors were ideally differentiated and together accounted for $67.48 \%$ of the variance. Table 1 shows the factor loadings of the twenty-six measures on the six labeled factors and Cronbach's alpha for each factor. Four of the factors were composed of only one item each and hence dropped from the dataset and excluded from all further analyses because they did not meet the minimum criterion of two items per factor (McCroskey \& Young, 1979). Additive indices were formed with the component measures loading under each of the remaining two factors.

Factor 1, labeled Curiosity $(\alpha=.89)$, accounted for $42.64 \%$ of the variance. The index was formed by summing the following measures: no benefits to use; use associated with weak will; interesting to know what using feels like; interesting to try; and using might be fun.

Factor 2, labeled Perception of Risk $(\alpha=.82)$, was formed by summing the following measures: safe usage; use leads to hard drugs; using any drug shortens lifespan; casual users progress towards abuse; and marijuana is so dangerous that it could destroy America's youth.

When a one-tailed $t$-was run with the Curiosity index, a significant effect for condition was found $[t(63)=2.5, p<.01]$ such that treatment participants agreed more with statements about being curious $(M=.70, S D=6.29)$ as compared to control participants $(M=-3.17, S D=6.00)$. This finding supports H2. For the Perception of Risk index, a significant main ef- fect for condition was found $[t(63)=2.7, p<.05]$ such that treatment participants agreed less with statements about the risks associated with illicit drug use $(M=-.05, S D=5.02)$ as compared to control participants $(M=2.78, S D=4.91)$.

The three analyses of Perception of Norms items yielded two significant effects. For estimates of usage in the past year, a significant effect for condition was found $[t(63)=$ $2.5, p<.01]$ such that treatment participants gave a higher estimate of the percentage of those who have used marijuana in the past year $(M=69.02, S D=2.97)$ as compared to those in the control group $(M=57.67, S D=3.42)$. For estimates of usage in the past month, a significant main effect for condition was found $[t(63)=2.36, p<.05]$ such that treatment participants gave a higher estimate of the percentage of those who have used marijuana in the past year $(M=49.51$, $S D=2.77)$ as compared to control participants $(M=39.5$, $S D=3.18)$. These results support $\mathrm{H} 1$.

A regression analysis showed that participants' estimates of behavior prevalence for annual and monthly users did not predict Curiosity, which fails to support H3. Prevalence estimates of daily users were negatively correlated with Curiosity $[F(1,60)=10.90, p<.01]$. This disconfirms H3 in that prevalence estimates for daily users negatively predicted Curiosity.

In sum, the hypotheses received various levels of support. H1 was partially supported, as treatment participants estimated a significantly higher percentage of high school students to have used marijuana at least once in the past year and at least once in the past month as compared to control participants. H2 was supported in that treatment participants were significantly more curious about using drugs as compared to control participants. H3 was partially unsupported and partially disconfirmed, with estimates of daily marijuana users negatively predicting Curiosity.

Despite that the ads aroused curiosity toward drug use, no evidence was generated concerning the psychological underpinnings of the process. In that participants' estimates of peer use did not predict - and in one case even negatively predicted-curiosity levels, the study was unable to uncover the reason why curiosity peaked. Unfortunately, this is not all too surprising. As Lowenstein (1994, p. 80) states, "the most basic problem that has occupied curiosity researchers and theorists is the underlying cause of curiosity," and the psychological literature dating back to the 1890s contains an extensive debate as to whether curiosity, itself, is a matter of cognition, affect, a mixture of both, or even a drive mechanism like thirst or hunger.

However, in that both of the main priming and curiosity hypotheses were supported, the findings suggest that the commercials activated participants' drug-related schema, as demonstrated by the increase in prevalence estimates among treatment participants, and that a gap (or gaps) in their experiential drug knowledge was highlighted, as evidenced by increased levels of curiosity. Although social comparison processes can serve to magnify the importance of a gap in knowledge, thereby further increasing curiosity, cognitively attending to social norms is not a necessary condition for curiosity arousal within Lowenstein's (1994) theoretical framework. Rather, simply highlighting a gap in knowledge 
Table 1. Factor Pattern of Illicit Drug Attitudes

\begin{tabular}{|c|c|c|c|c|c|c|}
\hline & Factor 1 & Factor 2 & Factor 3 & Factor 4 & Factor 5 & Factor 6 \\
\hline Measures & Curiosity & Perc. of Risk & Imp. to Others & Imp. to Self & Escape & Addictive \\
\hline Weak Will & -.73 & .15 & .02 & .28 & -.11 & .17 \\
\hline Feels Like & .83 & -.15 & -.21 & .24 & .15 & -.03 \\
\hline Fun & .84 & -.26 & -.10 & .18 & .11 & .03 \\
\hline Used Safely & .38 & -.62 & -.10 & -.02 & -.00 & .07 \\
\hline Parole & -.12 & .57 & .09 & -.15 & -.16 & -.04 \\
\hline Weekend Progress & -.28 & .70 & -.05 & .00 & -.11 & .01 \\
\hline Dangerous Youth & -.36 & .67 & -.10 & -.14 & .14 & .00 \\
\hline Imp. to Others & -.10 & .07 & .81 & .07 & .12 & -.02 \\
\hline Imp. Social & -.04 & .04 & -.08 & -.85 & -.04 & -.00 \\
\hline Problems & .14 & -.05 & .33 & -.04 & .75 & .14 \\
\hline Addictive & -.05 & .04 & -.02 & -.01 & .04 & .92 \\
\hline Legalized & .58 & -.46 & .23 & -.07 & -.01 & .12 \\
\hline Not Harmful & .66 & -.40 & .11 & .00 & .12 & -.03 \\
\hline Never Use & -.52 & .54 & -.22 & -.13 & -.11 & .08 \\
\hline Normal Experiment & .54 & -.26 & -.04 & .15 & .52 & -.12 \\
\hline Curious & .47 & -.22 & -.16 & .31 & .26 & -.08 \\
\hline Eigenvalue & 11.08 & 1.52 & 1.47 & 1.29 & 1.13 & 1.03 \\
\hline Cronbach's Alpha & .89 & .82 & $\mathrm{n} / \mathrm{a}$ & $\mathrm{n} / \mathrm{a}$ & $\mathrm{n} / \mathrm{a}$ & $\mathrm{n} / \mathrm{a}$ \\
\hline
\end{tabular}

on a particular topic is sufficient. Given that priming effects were shown and that curiosity was aroused, perhaps the simplest explanation for the effect is that the schema activation, itself, served to reveal knowledge gaps. If that is the case, then it is likely that other types of drug-related knowledge gaps were highlighted, too, but without proper measures, those effects went unnoticed.

Regarding experiential curiosity, such a characterization becomes more explanatory when one considers that a major focus of anti-drug ads is not simply "drugs," but rather a subset pertaining more specifically to the question of one's own drug use. If the commercials likewise more directly activated a subschema incorporating experiential knowledge of drugs, participants would have been more likely to notice gaps in that knowledge. To explain, Anderson's (1983) description of spreading activation likens the structure of a schema to a network of "pools" connected by gullies. In the analogy, stimuli serve to fill a particular pool with water, representing activation, and that water then flows out to nearby pools, which mirrors the process of spreading activation. The strength of the stimulus relates to the amount of water poured into the initial pool, and as such the activation 
can only spread so far to those concepts that are more closely related.

If the pool into which we initially pour the water represents the concept of "drugs" in general, then the activation would spread first to the most closely linked concepts, for example "illicit drugs," "prescription drugs," "over-thecounter drugs," and "other drugs" (e.g., caffeine, nicotine, and alcohol). It would then spread through those subschema, and so on, depending on attention intensity. In this instance, there is a question as to whether the activation would reach a concept such as "personal experience with illicit drugs," let alone move within that structure to highlight gaps in experiential knowledge. But, if the activation started with a subschema of "personal experience," it is much more likely that experiential concepts would become available; so it could be argued that when watching anti-drug ads, "personal experience" is directly activated, thereby calling attention to the specific information gaps.

However, anti-drug PSAs don't focus on personal use alone. They're also built on drug-related facts and terminology as well as the use (or non-use) of drugs by others, often conveying drug-related information, including the names of various drugs along with facts about the dangers and social usage of drugs. Therefore, if curiosity is aroused simply through drug ad priming, then along with experiential curiosity, the ads should also elicit curiosity toward drug-related facts, or "factual curiosity," as well as toward others' usage, or "social curiosity." We conducted a second study to test these possibilities, as well as to determine whether the rather counterintuitive findings from the initial study could be replicated.

Beyond simply testing whether or not anti-drug ads can evoke different types of curiosity, the study also examines the extent to which factual and social curiosity might play a role in producing experiential curiosity. From the results of Study 1, it is clear that we have not yet uncovered the theoretically-elusive underlying mechanisms of experiential curiosity arousal, and by Lowenstein's (1994) account, as outlined above, unveiling drug-related knowledge gaps regarding facts and social usage may lead one to question his or her own experiential knowledge. If this is the case, then factual and social curiosity would each be aroused, and they would influence participants' levels of experiential curiosity. On the other hand, if they do not predict experiential curiosity, then it can only be said that curiosity is aroused simply as a matter of priming drug-related schema and revealing knowledge gaps.

\section{MATERIALS AND METHODOLOGY: STUDY 2}

In replicating Study 1, Study 2 used the same procedures, with the following exceptions. The sample consisted of undergraduate college students $(\mathrm{N}=28)$ enrolled in an introductory journalism class, as opposed to high school seniors, and they were randomly assigned to condition by drawing slips of paper from a Ziploc ${ }^{\mathrm{TM}}$ bag at the start of class, resulting in fourteen participants per group. The conditions were run simultaneously by two female researchers, and the stimulus included three newer 30-second ads targeted at young adults (briefly described in Appendix $\mathrm{C}$ in the order of presentation) - as opposed to the four total ads shown in Study 1- which were inserted into a different episode of The Simpsons, "Bart Star." Items were added to the questionnaire by the researchers in order to assess factual and social curiosity, and questions unrelated to curiosity along with the perceptions of norms items were removed (see Appendix D).

\section{Data Analysis}

The resulting twenty-four questionnaire items were subjected to a factor analysis, and the procedure for determining the common factors and developing indices was the same as was done with the Likert scale items in Study 1. The indices obtained were checked for internal consistency and used as DVs, with condition as IV, in the analyses designed to test for differences in levels of experiential, factual, and social curiosity. These three analyses were one-tailed $t$-tests. Lastly, an ANCOVA was run with condition as IV, Experiential Curiosity as DV, and Factual and Social Curiosities as covariates, to determine whether the latter two forms of curiosity influenced the first.

\section{RESULTS}

A factor analysis of the twenty-four dependent measures yielded six factors which accounted for $79.39 \%$ of the variance. Table 2 shows the factor loadings of the twenty-four measures on the six labeled factors and Cronbach's alpha for each factor. Three of the factors were composed of only one item each and hence dropped from the dataset and excluded from all further analyses, yielding three total factors. Factor 1, labeled Experiential Curiosity $(\alpha=.71)$, accounted for $26.88 \%$ of the variance, and it was formed by summing the following seven measures: healthy experimentation; no benefits to use; OK if not caught; interesting to try; use not harmful; use fun; and normal to experiment. Factor 2, labeled Factual Curiosity ( $\alpha=.86$ ), accounted for $16.75 \%$ of the variance, and it was formed by summing the following measures: unfamiliar terms; why popular; why a problem; why use; and what terms mean. Factor 3, labeled Social $\mathrm{Cu}$ riosity $(\alpha=.90)$, accounted for $12.19 \%$ of the variance, and it was formed by summing the following measures: what kinds of drugs people use; how many peers use; and what kinds of people use drugs.

One significant effect resulted from the analyses. For the Experiential Curiosity index, a significant effect for condition was found $[t(26)=-2.056, p<.05]$ such that treatment participants $(M=5.30, S D=3.72)$ agreed more with statements about being curious (and less with a negatively-worded statement) as compared to control participants $(M=0.14$, $S D=8.62$ ). No significant effect for condition was found on either the Factual Curiosity index $[t(26)=0.228, p>.05]$ or the Social Curiosity index $[t(26)=0.130, p>.05]$. In the ANCOVA run to assess the influence of Factual and Social $\mathrm{Cu}$ riosity on Experiential Curiosity, condition continued to be a significant predictor of Experiential Curiosity $[F(1,24)=$ $4.06, p=.05$ ], with neither of the covariates showing any statistical significance. Therefore, we can rule out Factual and Social Curiosities as playing a role.

\section{DISCUSSION}

In both experiments, a significant effect for the presence of the ads was obtained on a measure of experiential curios- 
Table 2. Factor Pattern of Illicit Drug Curiosity

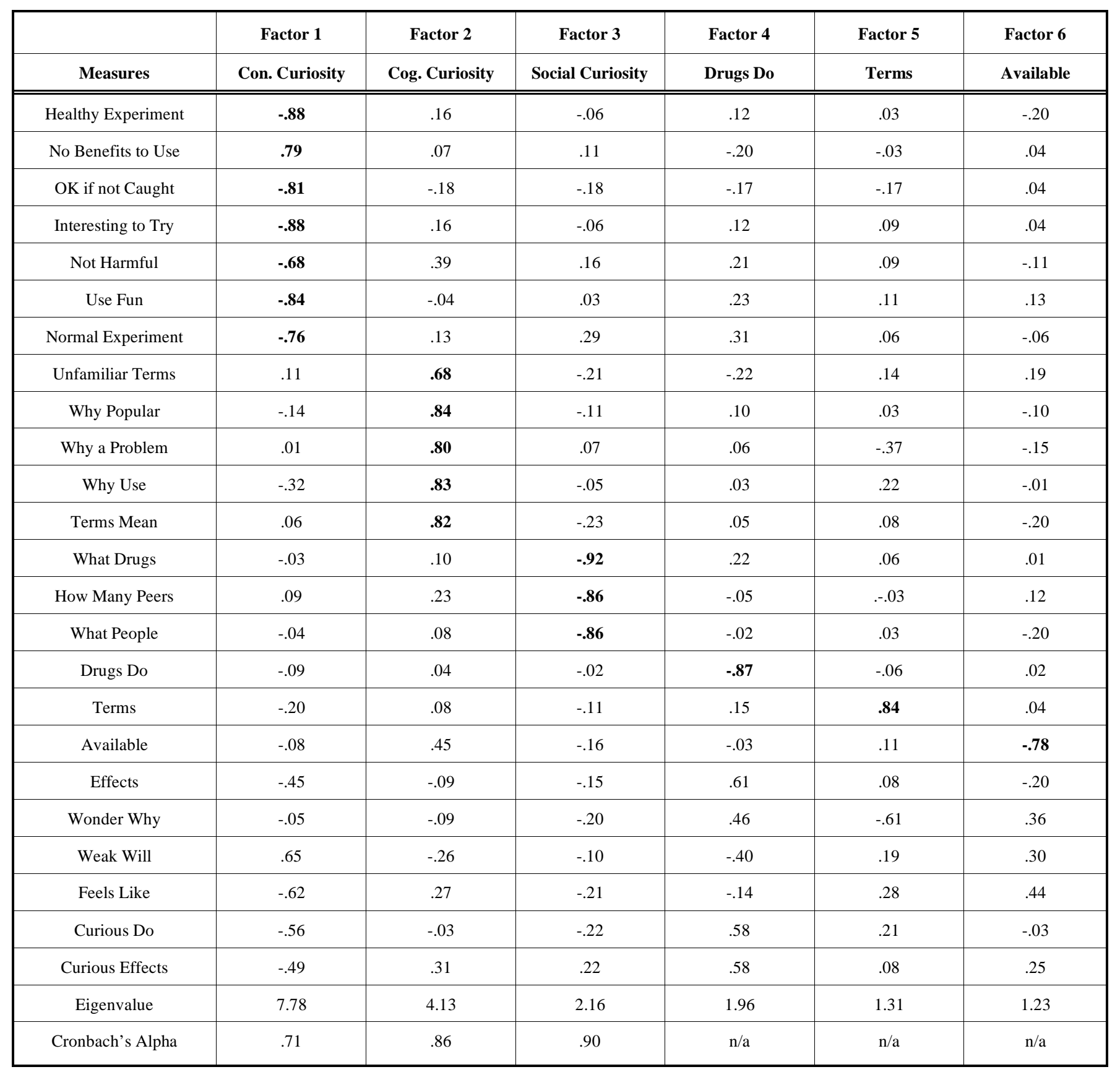

ity. Participants whose stimuli contained anti-drug ads were more curious about using illicit drugs as compared to those whose stimulus contained no PSAs. These results should be seriously considered, as it has been consistently recognized in psychological research that curiosity is one of the most potent motivational forces for human behavior (Lowenstein, 1994). It has been shown to prompt impulsive behaviors (e.g., Hartig \& Kanfer, 1973; Kanfer \& Zich, 1974), and it can cause people to willfully act against their own selfinterest (Lowenstein, 1994). Moreover, once activated, curiosity can grow stronger until it is satiated, and, perhaps counterintuitively, as people obtain more information about a subject, the prospect of future curiosity arousal can become even more likely because acquiring new information reduces the perceived quantity of missing information. This in turn may cause one to perceive particular knowledge gaps as that much more manageable.

Unfortunately, neither study produced sufficient insight into the underlying mechanisms that cause anti-drug ads to arouse experiential curiosity. In the first study, it was hypothesized that, through a process of social comparison, elevated perceptions of illicit drugs' social prevalence would highlight the importance of missing experiential knowledge, thereby provoking curiosity toward drug use. Although it was established that anti-drug ads prime participants to imagine that more of their peers use drugs (see Berkowitz, 1984), a regression analysis showed that none of the participants' estimates of drug use prevalence positively predicted 
their score on the "Curiosity" index as hypothesized. Participants' curiosity was not shown to be a function of their assumptions about the percentage of their peers who they believe use-or rather have experiential knowledge of-illicit drugs.

In a second study, it was proposed that anti-drug ads may not only arouse experiential curiosity, but that they might also influence factual and social curiosity. This is because, as opposed to simply activating an overall "drug" schema, PSAs should more specifically activate drug-related subschema relating to one's own use (experiential), drug-related information (factual), and use among others (social). While the replication revealed that participants' experiential curiosity increased, which remains consistent with the explanation that "personal experience" information gaps were highlighted by the anti-drug ad stimulus, Study 2 did not provide evidence that participants became more curious about factual or social aspects of illicit substances, nor did it show that experiential curiosity was aroused by factual or social curiosity. Unfortunately, perhaps the only explanation we can confidently forward given the present data is that anti-drug ads simply prime viewers to think about their personal experience with drugs, and this can in turn lead them to become curious about taking drugs and filling that information gap.

It may be that participants perceived the knowledge set pertaining to experiential drug information as much more manageable than that of factual or social information, and "the intensity of curiosity directed at a particular item should be related positively to its ability to resolve uncertainty (i.e., to close the information gap)" (Lowenstein, 1994, p. 88). Stated differently, when one thinks of all the information to be known about drug-related facts or about drug use as a social phenomenon, the sheer magnitude of the perceived knowledge set could deter the onset of curiosity, whereas, with regard to drug use, one might intuitively imagine that finding out what "using drugs feels like" could be solved with a single experience.

Experiential information may also be inherently more curiosity-arousing than factual or social information. Just as some people are more prone to curiosity, certain topics are more likely to evoke curiosity than others. In particular, Lowenstein (1994; p. 93) suggests that "anything having to do with the self [is] almost universally interesting." This would help explain why experiential curiosity arousal was shown where factual and social curiosity were not, as the question of whether or not to use drugs oneself is more personal than wondering what drug-related words mean, what kinds of people use drugs, or how many people use drugs.

Concerning anti-drug ads, the simple act of suggesting abstinence from illicit drug use might beg the question of whether or not to try illicit drugs, and the posing of a question to which the individual does not possess the answer is the most straightforward of all curiosity-inducing stimuli, because it directly draws attention to a specific information gap.

Two final stimulus-bound possibilities predicted by information-gap may not apply to all anti-drug PSAs, but they do relate to spots presented in the studies. First, two of the commercials shown in Study 1 ("Nothing Happens" and "If everyone did...") and one in Study 2 (“Ashley") formulate scenarios that they do not resolve, showing a sequence of events leading to an unknown outcome. Information-gap predicts that when such a scenario occurs, it is likely that one will become curious to know the outcome. In the case of drug use, this may lead to experimentation undertaken to determine the outcome for oneself.

Another possibility relating to a spot shown in Study 1 pertains to violating expectations. The commercial entitled "If everyone else did..." suggests that adolescents may follow the crowds and experiment with various deviant behaviors such as wearing an outlandish hairstyle or getting body parts pierced, but it ends by suggesting that trying drugs won't place the viewer in the mainstream because adolescent drug users are but a small minority, which may violate expectations about its very placement. At the first suggestion of drug use, the viewer probably begins to imagine that the commercial will say something like "being 'cool' isn't worth the risk." However, the idea lingers for a few seconds before the commercial simply states that drugs aren't popular. "Of course," the viewer may well imagine, "if nobody is using drugs, then why is this commercial on?" This could lead the viewer to believe that the commercial is less than honest, and that maybe doing drugs does have its benefits, despite the hype.

Depending on individual experience, anti-drug PSAs may evoke curiosity among those who have already been exposed to illicit drugs by evoking latent memories. Information-gap explains that past realizations can serve as a reference point against which one's present state is compared. Therefore, beyond activating memories of drug use and making the topic salient to the user, the activated memories might serve as a challenge to find out how illicit drugs would affect her or him today. Another prospect is that anti-drug ads might alert a user to a particular information gap by pointing out drug-related information of which he or she was previously unaware. This could provoke curiosity in that it might lend the viewer the desire to investigate through experiencing drugs first-hand, or in that it may show the user that he or she does not possess as extensive a knowledge of illicit drugs as previously imagined.

Although the priming effects shown in Study 1 do not directly implicate a source of curiosity arousal, the discovery has important implications. The finding suggests that a paradoxical relationship may exist for mass mediated messages created to decrease viewers' perception of illicit drug use prevalence, as it demonstrates that the mere mention of drugs in anti-drug PSAs inherently works to increase viewers' prevalence estimates. One of the commercials shown in Study 1 ("If everyone else did...") states specifically that drug use prevalence is lower than one would imagine, yet viewing the commercials led to increased estimates of illicit drug use prevalence.

Since the goal of many commercials is to instill abstinence through promoting the belief that drug use is not the norm, and since abstinence cannot be presented without mentioning from what one should refrain, perhaps a viable option is instead to provide examples of alternative activities. Of course, the fact that the activities are alternatives cannot be mentioned either because, again, this requires stat- 
ing that to which the activities are alternative. This suggestion is similar to that of Tybout, Calder, and Sternthal (1981), who showed that refuting a rumor about McDonald's hamburgers containing worms yielded significantly worse evaluations of the restaurant than inducing participants to think of other aspects of McDonald's or practicing no rumor control whatsoever, even when participants believed the refutation: simply point attention elsewhere; don't make the idea salient.

The priming effects shown seem to have occurred in a relatively straightforward way. Suggestions and examples of drug use made the incoming and stored information available for cognitive use, and this in turn led to exaggerated estimates of social prevalence. As no effect was found for estimates of daily users, it might be argued that priming does not affect estimates of short-term prevalence. However, the results may also reflect the nature of the question itself. This item specifically asks participants to estimate the percentage of daily users, while the other two items ask for the percentage who have used at least once within the past month and year. At first, the difference may go unnoticed, but the distinction is clearer when thought of in terms of experimentation with drugs versus habitual use. That treatment participants gave considerably higher estimates of daily user prevalence implies priming is at work, but in that their estimates weren't significantly higher suggests that it may be more difficult to envision habitual use amongst one's peers.

In that participants' estimates of the percentage of daily users negatively predicted curiosity, the study may have unwittingly uncovered a promising area for future research into the boundaries of curiosity arousal as a function of consuming drug ads. Psychological theories of curiosity dating back to James' (1950) seminal work indicate that, up to a point, curiosity and fear are often sparked by the same stimulus, but, when the source of fear becomes too proximal, trepidation overrides the tendency to explore (Lowenstein, 1994). If the negative correlation between estimates of daily users and experiential curiosity reflects a process wherein the prospect of drug dependence "brought home" the dangers of drug use for participants by invoking the notion of drug dependence, then perhaps stressing the likelihood of progressing to habitual use could countermand people's propensity to probe. However, the method by which these data were collected does not allow us to establish a causal relationship between estimates of peer use and experiential curiosity. Moreover, techniques used in the present sets of advertisements seem not to have conveyed such a level of threat proximity. The spots "Nothing Happens" from Study 1 and "Everybody's Doing It" from Study 2 raise the specter of lifetime dependence, yet each study unearthed curiosity-arousing effects.

Lastly, while these studies demonstrate that anti-drug ads can increase curiosity toward using illicit substances, the experimental method used does not allow for generalizable predictions as to the extent of the problem (Aronson, Brewer, \& Carlsmith, 1985). That is, as with all experimental studies that are run in controlled settings, the external validity of the results are in question, and no claims are made as to the percentage of adolescents whose curiosity might be aroused. However, given that the two studies found consistent results across two geographically separate locations and with both high school and introductory class college students increase our confidence in the robustness of the curiosity effect.

It must be kept in mind that the main objective of experimental research is to maximize internal validity (Berkowitz \& Donnerstein, 1982), but in these studies, ecological validity, which typically helps increase external validity (Brewer, 2000), was also a concern due to the counterintuitive nature of the hypotheses. As such, a number of steps were taken to increase ecological validity. The experimental sessions took place in classrooms, where viewing television programming occurs often among students in their day-to-day lives. Also, the anti-drug ads shown were edited into the regular commercial breaks of the program as aired. The programming shown was targeted toward and often watched by the demographics represented by the participants, and the ads shown were also targeted to the participants' demographics. Yet, given the experimental nature of the studies and the non-probability samples used, the degree of generalizability is a concern.

With these caveats in mind, as has been argued elsewhere (Kelder, Pechmann, Slater, Worden, \& Levitt, 2002; Sundar, 1999), it is suggested that a range of methodological approaches should be applied to the study of anti-drug ads. While experiments lack external validity, they offer greater certainty with regard to viewing the specific ads and the responses that they cause. At the same time, while surveys are designed to produce generalizable results, it is uncertain from the results as to whether respondents actually viewed the ads, which ads were seen, or how the timing of exposure relates to drug-related responses (Sundar, 1999). Focus groups can also be a helpful formative research tool for exploring the ways in which ads might be modified to suit their audiences prior to airing (Andsager, Austin, \& Pinkleton, 2002). However, focus group responses related to the assumed effects of the ads are questionable, as participants' introspective access to the influence of stimuli is severely limited (Nisbett \& Wilson, 1977). In accounting for the advantages and disadvantages of various methodologies, triangulating results from the larger body of research yields the most comprehensive, and likely the most accurate, insight into the nature, uses and effects of anti-drug ads.

\section{CONCLUSION}

Methodological concerns notwithstanding, each or all of the mechanisms governing the above-mentioned alternative explanations for curiosity arousal may be at least partially responsible for the demonstrated effects. Discovering which of them plays a role and in what way appears vital in future PSA study. Given the elusiveness of determining the processes that induce curiosity (Lowenstein, 1994), a range of possibilities remain that might be fruitful to examine in future research. A number of these are outlined above, including: 1) that filling experiential information gaps may be seen as a more easily attainable goal as opposed to satiating other types of curiosity; 2) subjects related to the self can be particularly curiosity-arousing; and 3) viewers may see antidrug ads as posing the question of whether or not to experiment with drugs. Moreover, specifically regarding the ads used in the present studies, it was suggested that formulating 
unresolved scenarios and violating expectations represent techniques that are particularly likely to arouse curiosity. Beyond calling for future research into these possibilities, it seems safe to suggest that anti-drug ad producers avoid using such techniques pending further investigation.

Although it may be that "the question of curiosity's underlying cause is inherently unanswerable because it is always possible that curiosity stems from some as yet unidentified, more basic drive or motive" (Lowenstein, 1994, p. 84), narrowing down the list of possible culprits could significantly increase our ability to reduce the likelihood that viewers might be provoked to experiment with illicit substances as a result of consuming anti-drug ads.

\section{REFERENCES}

Anderson, J. R. (1983). The architecture of cognition. Cambridge, MA: Harvard University.

Andsager, J. L., Austin, E. W., \& Pinkleton, B. E. (2002). Gender as a variable in interpretation of alcohol-related messages. Communication Research, 29 (3), 246-69.

Aronson, E., Brewer, M., \& Carlsmith, J. M. (1985). Experimentation in social psychology. In G. Lindzey \& E. Aronson (Eds.), The Handbook of Social Psychology, Vol. 1 (pp. 441-86). New York: Random House.

Atkin, C. K. (2001). Theories and principles of media health campaigns. In R. E. Rice \& C. K Atkin (Eds.), Public Communication Campaigns (3rd. ed., pp. 49-68). Thousand Oaks, CA: Sage.

Atkin, C. K., \& Freimuth, V. S. (2001). Formative evaluation research in campaign design. In R. E. Rice \& C. K Atkin (Eds.), Public Communication Campaigns (3rd. ed., pp. 125-45). Thousand Oaks, CA: Sage.

Bachman, J. G., Wadsworth, K. N., O’Malley, P. M., Johnston, L. D., \& Schulenberg, J. E. (1997). Smoking, drinking, and drug use in young adulthood: The impacts of new freedoms and new responsibilities. Mahwah, NJ: Lawrence Erlbaum Associates.

Baker, S. M., Petty, R. E., \& Gleicher, F. (1991). Persuasion theory and drug abuse prevention. Health Communication, 3(4), 217-27.

Berkowitz, L. (1984). Some effects of thoughts on anti- and pro-social influences of media events: A cognitive-neoassociation analysis. Psychological Bulletin, 95, 410-27.

Berkowitz, L., \& Donnerstein, E. (1982). External validity is more than skin deep. American Psychologist, 37, 245-57.

Brewer, M. (2000). Research design and issues of validity. In Reis, H. and Judd, C. (Eds.), Handbook of Research Methods in Social and Personality Psychology. Cambridge: Cambridge University.

Black, G. (1991). Changing attitudes toward drug use: The effects of advertising. In E. L. Donohew (Ed.), Persuasive Communication and Drug Abuse Prevention. Hillsdale, NJ: Lawrence Erlbaum.

Carifio, J. (1994). Sensitive data and students' tendencies to give socially desirable responses. Journal of Alcohol \& Drug Education, 39(2), 74-84.

Carifio, J., \& Biron, R. (1978). Collecting sensitive data anonymously: The CDRGP technique. Journal of Alcohol \& Drug Education, 23(2), 47-66.

Chappel, J. N., Veach, T. L., \& Krug, R. S. (1985). The Substance Abuse Attitude Survey: An instrument for measuring attitudes. Journal of Studies on Alcohol, 46(1), 48-52.

Chen, K., \& Kandel, D. B. (1995). The natural history of drug use from adolescence to the mid-thirties in a general population sample. American Journal of Public Health, 85, 41-47.

Cialdini, R. B., Reno, R. R., \& Kallgren, C. A. (1990). A focus theory of normative conduct: Recycling the concept of norms to reduce littering in public places. Journal of Personality and Social Psychology, 58(6), 1015-26.

Davis, N. (1997). Persuasive communication in the mass media: Implications for preventing drug-related behavior among youths. Journal of Child \& Adolescent Substance Abuse, 6(2), 49-56.

DeWit, D. J., Offord, D. R., \& Wong, M. (1997). Patterns of onset and cessation of drug use over the early part of the life course. Health Education and Behavior, 24, 746-58.
Donohew, L., Lorch, E., \& Palmgreen, P. (1991). Sensation-seeking and targeting of televised anti-drug PSAs. In L. Donohew, H. E. Sypher, \& W. J. Bukowski (Eds.), Persuasive Communication and Drug Abuse Prevention (pp. 209-28). Hillsdale, NJ: Erlbaum.

Dovidio, J. F., \& Fazio, R. H. (1991). New technologies for the direct and indirect assessment of attitudes. In J. M. Tanur (Ed.), Questions about Questions: Inquiries into the Cognitive Bases of Surveys, pp. 204-37. New York: Russell Sage.

Everett, M. W. \& Palmgreen, P. (1995). Influences of sensation seeking, message sensation value, and program context on effectiveness of anti-cocaine public service announcements. Health Communication, 7, 225-48.

Fazio, R. H. (1990). Multiple processes by which attitudes guide behavior: The MODE model as an integrative framework. Advances in Experimental Social Psychology, 23, 75-109.

Fazio, R. H., Herr, P. M., \& Powell, M. C. (1992). On the development and strength of category-brand associations in memory: The case of mystery ads. Journal of Consumer Psychology, 1, 1-13.

Fazio, R. H., \& Towles-Schwen, T. (1999). The MODE model of attitudebehavior processes. In S. Chaiken \& Y. Trope (Eds.), Dual-Process Theories in Social Psychology (pp. 97-116). New York: Guilford.

Green, D. (1990). Instrument for the measurement of individual and societal attitudes towards drugs. International Journal of the Addictions, $25,141-57$

Hartig, M., \& Kanfir, F. H. (1973). The role of verbal self-instructions in children's resistance to temptation. Journal of Personality and Social Psychology, 25, 259-67.

Hawkins, J. D., Graham, J. W., Maguin, E., Abbott, R., Hill, K. G., Catalano, R. F. (1997). Exploring the effects of age of alcohol use initiation and psychosocial risk factors on subsequent alcohol misuse. Journal of Studies on Alcohol, 58, 280-90.

Iyengar, S., Peters, M. D., \& Kinder, D. R (1982). Experimental demonstrations of the "not-so-minimal" consequences of television news programs. American Political Science Review, 76, 848-58.

James, W. (1950). Principles of Psychology (Vol. 2). New York: Holt. (original work published 1890).

Johnston, L. D., O'Malley, P. M., \& Bachman, J. G. (2003). Monitoring the Future national survey results on drug use, 1975-2002. Volume I: Secondary school students (NIH Publication No. 03-5375). Bethesda, MD: National Institute on Drug Abuse, $520 \mathrm{pp}$.

Kane, C. (1998, July 9). A federal agency starts a paid campaign today to influence young people to stay away from drugs. New York Times, D3.

Kanfer, F. H., \& Zich, J. (1974). Self-control training: The effects of external control on children's resistance to temptation. Developmental Psychology, 10, 108-115.

Kelder, S. H., Pechmann, C., Slater, M. D., Worden, J. K., \& Levitt, A. (2002). The National Youth Anti-drug Media Campaign. American Journal of Public Health, 92 (8), 1211-12.

Kelly, K., \& Edwards, R. (1992). Observations: Does discussion of advertising transform its effects? Yes...sometimes: A case among college students and their response to anti-drug advertising. Journal of Advertising Research, 32(4), 79-83.

Lowenstein, G. (1994). The psychology of curiosity: A review and reinterpretation. Psychological Bulletin, 116, 75-98.

McCroskey, M., \& Young, T. (1979). The use and abuse of factor analysis in communication research. Human Communication Research, 4, 375-82.

McGuire, W. J. (2001). Input and output variables currently promising for constructing persuasive campaigns. In R. E. Rice \& C. K. Atkin (Eds.), Public Communication Campaigns (3rd. ed.), pp. 22-48. Thousand Oaks, CA: Sage.

Myers, D. G. (1987). Social Psychology (2nd ed.). New York: McGraw Hill.

Orne, M. T. (1969). Demand characteristics and the concept of quasicontrols. In R. Rosenthal \& R. L. Rosnow (Eds.), Artifact in Behavioral Research. New York: Academic Press.

Paisley, W. J. (2001). Public communication campaigns: The American experience. In R. E. Rice \& C. K Atkin (Eds.), Public Communication Campaigns (3rd. ed.), pp. 3-21. Thousand Oaks, CA: Sage.

Palmgreen, P., \& Donohew, L. (1994). Reaching at-risk populations in a mass media drug abuse prevention campaign. Drugs \& Society, 8 (3/4), 29-45

Palmgreen, P., Donohew, L., Lorch, E. P., \& Rogus, M. (1991). Sensation seeking, message sensation value, and drug use as mediators of PSA effectiveness. Health Communication, 3, 217-27. 
Palmgreen, P., Lorch, E. P., Donohew, L., \& Harrington, N. G. (1995). Reaching at-risk populations in a mass media drug abuse prevention campaign: Sensation seeking as a targeting variable. Drugs \& Society, 8(3-4), 29-45.

Petty, R. E., Baker, S. M., \& Gleicher, F. (1991). Attitudes and drug abuse prevention: Implications of the elaboration likelihood model of persuasion. In L. Donohew, H. E. Sypher, \& W. J. Bukowski (Eds.), Persuasive communication and drug abuse prevention (pp. 71-90). Hillsdale, NJ: Erlbaum.

Reis, E. C., Duggan, A. K., Adger, H., Jr., \& DeAngelis, C. (1994). The impact of anti-drug advertising: Perceptions of middle and high school students. The Archive of Pediatric and Adolescent Medicine, $148,1262-68$.

Salmon, C. T., \& Murray-Johnson, L. (2001). Communication campaign effectiveness: Critical distinctions. In R. E. Rice \& C. K. Atkin (Eds.), Public Communication Campaigns (3rd. ed., pp. 49-68). Thousand Oaks, CA: Sage.
Skinner, E. R., \& Slater, M. D. (1995). Family communication patterns, rebelliousness, and adolescent reactions to anti-drug PSAs. Journal of Drug Education, 25, 343-355.

Slater, M. D., \& Rasinski, K. A. (2005). Media exposure and attention as mediating variables influencing social risk judgments. Journal of Communication, 55 (4), 810-827.

Slater, M. D., \& Rouner, D. (1996). Value affirmation and value-protective processing of alcohol education messages that include statistical evidence or anecdotes. Communication Research, 23, 210-35.

Sundar, S. S. (1999). Statement before the subcommittee on criminal justice, drug policy, and human resources of the United States House of Representatives: Hearing on the Office of National Drug Control Policy (ONDCP) National Youth Anti-Drug Media Campaign.

Tybout, A. M., Calder, B. J., \& Sternthal, B. (1981). Using information processing theory to design marketing strategies. Journal of Marketing Research, 18, 73-79.

Wartella, E., \& Middlestadt, S (1991). The evolution of models of mass communication and persuasion. Health Communication, 3(4), 205215 .

(c) Wagner and Sundar; Licensee Bentham Open.

This is an open access article distributed under the terms of the Creative Commons Attribution License (http://creativecommons.org/licenses/by/2.5/), which permits unrestrictive use, distribution, and reproduction in any medium, provided the original work is properly cited. 


\section{Appendix A: Study 1 Ad Stimulus Descriptions}

1) "Nothing Happens" (30 sec.): Shot in black-and-white, this PSA depicts two friends sharing a marijuana cigarette. The friends, both white males, sit in a dimly-lit room backlit through a drapery-covered window. The two friends appear to be middle-class, as the room (located in one of the males' (Eddie's) parents' house) is comfortably furnished with a reclining lounge chair and a work desk. As the commercial begins, the male in the foreground (Eddie) mocks what he has heard about using marijuana, sarcastically contending "Marijuana can mess you up," as he laughs and takes a puff from a marijuana cigarette. He then asks his friend whether marijuana has caused him (Eddie) to "get into other drugs and start mugging people." Eddie then answers his own question: "Nah, I didn't do anything. In fact, I'd say I'm exactly the same as when I smoked my first joint." Eddie's mother then calls in from an off-screen room, "Eddie, did you even look for a job today?" Hurriedly looking around with an apprehensive glance, Eddie quickly waves the smoke away and replies "No, ma." The screen fades to gray with the words "Nothing happens with marijuana" appearing in the center, written in white, and "Partnership for a Drug-Free America" materializing at the bottom, also written in white, as an announcer states "Marijuana can make nothing happen to you, too."

2) "If everyone did" (30 sec.): - This quickly-edited PSA mixes live-action high-contrast color scenes, shot with moving cameras, and shots of jittery words written in white on a black background. The live action shots depict various white adolescents displaying numerous socially deviant behaviors. As youth with neon-colored hair styled in "mohawks" are shown, a male announcer states in a voice-over, "You might decide to change your hair...if everyone else did." The words "hair" and "cut" appear intermittently. The announcer then says, "You might decide to get a tattoo...if everyone else did" as numerous flamboyant tattoos cross the screen. The letter "U" is shown between two of the shots. Next, various body piercings are shown, and the announcer says, "You might decide to get something pierced...if everyone else did." The word "nose" and an upward facing arrow appear intermittently. Finally, the backs of several recliner chairs are shown sitting in the middle of a desert. As the camera winds its way around to the front of the chairs, the announcer states, "You might even decide to smoke pot...if everyone else did." The words "guess," "what," and a set of three question marks flash on the screen whilst the live-action shot continues. When the camera reaches the fronts of the chairs, viewers see a white adolescent sitting alone in the middle one, holding a marijuana cigarette, and staring at it curiously. The announcer then states, "Well, guess what...not everyone else does." The word "PICTURE" appears and the screen mimics a television being turned off. As the commercial ends, the words "Partnership for a Drug-Free America" are shown (in white but not shaking) in silence.

3) "Celebrity Endorsement" (15 sec.): This PSA mimics a slide show of various celebrities who have died from drug overdose. Black-and-white stills of Janis Joplin, Jim Morrison, John Belushi, and River Phoenix are shown with their names, the year they were born, and the year they died underscoring their faces. A noise which sounds like a slide projector switching images falls between each of the shots as a right-to-left black wipe clear the screen and the next picture moves on from the left. A male announcer then states in a voice-over, "They say the best way to get your message across is to put celebrities in your advertisements...we hope they're right." The last "slide" says "Partnership for a Drug-Free America" in white lettering on a black background.

4) "Fried Egg" (30 sec.): - This PSA is composed of a single color shot of a middle-aged middle-class white male in a kitchen. As the commercial begins, he is standing against a row of cupboards with his arms crossed and wearing a disapproving look. Light is beaming in from a window to his right, illuminating the right side of his face. The man asks, "Is there anyone out there who still isn't clear about what doing drugs does?" He then says, "OK, last time." The camera follows him as he walks across the room and grabs an egg from a carton on the stove. He holds the egg up and says, "This is your brain," as he points to the egg. He then points to a skillet on the stove and says, "This is drugs." He cracks the egg on the side of the pan and dumps the unborn chicken ovulation into the heated pan. It begins to fry, and the man says "This is your brain on drugs. Any questions?" As the contents of the skillet continue to sizzle and coagulate, the screen fades to black with the words "Partnership for a Drug-Free America" written in white. 


\section{Appendix B: Study 1 Questionnaire}

\section{ATTITUDE SURVEY}

Please circle the answer that best describes how

much you agree with each of the statements below.

$\mathrm{D}=$ Very Much Disagree $\mathrm{d}=$ somewhat disagree $\mathrm{u}=$ undecided

$\mathrm{a}=$ somewhat agree $\mathrm{A}=$ Very Much Agree

1. There are no benefits to using marijuana.

2. Marijuana should be legalized.

3. Marijuana can be used safely by a person who is mentally healthy.

4. Persons convicted of the sale of illicit drugs should not be eligible for parole.

5. Marijuana use leads to mental illness.

6. Many drugs are so addictive that no one can really recover once he/she becomes an addict.

7. Marijuana use leads to using hard drugs.

8. It's OK to try marijuana if you know you won't get caught.

9. Marijuana use among teenagers can be healthy experimentation.

10. Daily use of one marijuana cigarette is not necessarily harmful.

11. All marijuana use leads to addiction.

12. Marijuana use is associated with a weak will.

13. Others take marijuana use much more seriously than I do.

14. It would be interesting to know what using marijuana feels like.

15. Using any hard drugs shortens one's life span.

16. Weekend users of drugs will progress to drug abuse.

17. Personal use of drugs should be legal in one's own home.

18. Using marijuana is not harmful.

19. It might be interesting to try marijuana.

20. Almost anyone would turn to drugs if their problems were great enough.

21. Using marijuana might be fun.
D

$\begin{array}{lllll}\text { D } & \text { d } & \text { u } & \text { a } & \text { A } \\ \text { D } & \text { d } & \text { u } & \text { a } & \text { A }\end{array}$

$\begin{array}{lllll}\text { D } & \text { d } & \text { u } & \text { a } & \text { A }\end{array}$

$\begin{array}{lllll}D & d & u & a & A\end{array}$

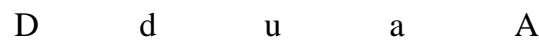

$\begin{array}{lllll}\text { D } & \text { d } & \text { u } & \text { a } & \text { A } \\ \text { D } & \text { d } & \text { u } & \text { a } & \text { A }\end{array}$

$\begin{array}{lllll}\text { D } & \text { d } & \text { u } & \text { a } & \text { A }\end{array}$

$\begin{array}{lllll}\text { D } & \text { d } & \text { u } & \text { a } & \text { A }\end{array}$

$\begin{array}{lllll}\text { D } & \text { d } & \text { u } & \text { a } & \text { A }\end{array}$

$\begin{array}{lllll}\mathrm{D} & \mathrm{d} & \mathrm{u} & \mathrm{a} & \mathrm{A}\end{array}$

$\begin{array}{lllll}\text { D } & \text { d } & \text { u } & \text { a } & \text { A }\end{array}$

$\begin{array}{lllll}\text { D } & \text { d } & \text { u } & \text { a } & \text { A }\end{array}$

$\begin{array}{lllll}\text { D } & \text { d } & \text { u } & \text { a } & \text { A }\end{array}$

$\begin{array}{lllll}\text { D } & \text { d } & \text { u } & \text { a } & \text { A }\end{array}$

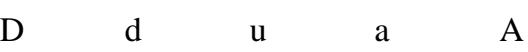

$\begin{array}{lllll}\mathrm{D} & \mathrm{d} & \mathrm{u} & \mathrm{a} & \mathrm{A}\end{array}$

D $\quad$ d $\quad$ u $\quad$ a $\quad$ A

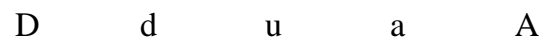

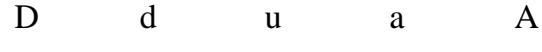

D $\quad$ d $\quad u \quad a \quad$ A


22. People should never use marijuana.

23. It can be normal for a teenager to experiment with drugs.

24. Marijuana is so dangerous that it could destroy the youth of our country

if it wasn't controlled by law.

25 . It is normal to be curious about marijuana.

26. Marijuana use is a very important social issue.
$\mathrm{D}$

D

d

u

a

A

$\begin{array}{lllll}D & d & \text { u } & \text { a } & \text { A } \\ \text { D } & \text { d } & \text { u } & \text { a } & \text { A }\end{array}$

$\begin{array}{lllll}\mathrm{D} & \mathrm{d} & \mathrm{u} & \mathrm{a} & \mathrm{A}\end{array}$

What percentage of high school students do you believe have used marijuana at least once in the past year?

What percentage of high school students do you believe have used marijuana in the past month?

What percentage of high school students do you believe is a daily marijuana user? 


\section{Appendix C: Study 2 Ad Stimulus Descriptions}

1) "Ashley" (30 sec.): This ad focuses on a white female named Ashley talking about her experiences with drugs. She first describes what it was like, saying that it gave her a warm feeling and made her feel like she was floating. She then says she swore that she would never "shoot up" and that when she started "doing dope," the fighter in her died and the part of her that found joy in life and day-to-day living died. The spot, mainly composed of a black-and-white close-up shots, fades twice to and from color stills of Ashley in years previous, and her voiceover continues through both. The first color shot shows her at age eighteen, and a caption explains that at the time she was president of her high school class. The second color shot shows her at age twenty-four as an advertising executive. As Ashley returns to the screen and the commercial closes, we see a caption explaining that she is currently a twenty-eight year-old heroin addict. The image of Ashley then fades to black, with the words "Partnership for a Drug-free America" in white, centered on the screen.

2) "Thin Ice" (30 sec.): This commercial begins with a subjective camera shot looking down at a foot steeping into snow then breaking through the ice below. The shot then fades to several subjective-camera underwater shots-all connected with fades - of hands trying to break through a sheet of ice confining the person below the surface. Finally, the commercial cuts to an objective camera shot from above the surface, and below the ice is a blurry vision of the figure trying to break free. During this objective camera shot, we hear a voice-over stating "Welcome to heroin. Enjoy your stay." The ad then cuts to black, with the words "Partnership for a Drug-free America" in white, centered on the screen.

3) "Everybody's Doing It" (30 sec.): This PSA begins with a high-angle shot of a college-age male lying against a bathroom wall and shivering. The word "Heroin," written in metallic lavender script lettering, then cascades onto the screen. A shot of the same person from the same angle in the same bathroom, this time showing the man's back as he lies on the floor shivering in the fetal position, comes on the screen via a jump cut, and the camera then closes in on his left shoulder and shows his twitching back muscles. Another jump cut takes us to a position above the male as he continues to shiver, now lying on his back. This shot reveals a scar or tattoo on the left side of his neck. The camera then pans to his feet, showing that his whole body is writhing. A third jump cut brings us a medium-close shot of the male hanging onto the side of the toilet, his head resting on the side of the bowl as he convulses. As before, the word "Heroin" comes on the screen. However, this time it is accompanied below by the phrase "Looking Good!" printed in smaller lavender print. The ad then cuts to black, with the words "Partnership for a Drug-free America" in white, centered on the screen. An upbeat jingle, "Everybody's Doing It, Heroin," plays for the duration of the ad. 


\section{Appendix D: Study 2 Questionnaire}

\section{ATTITUDE SURVEY}

Please circle the answer that best describes how much you agree with each of the statements below.

$\mathrm{D}=$ Very Much Disagree $\mathrm{d}=$ somewhat disagree $\mathrm{u}=$ undecided

$\mathrm{a}=$ somewhat agree $\mathrm{A}=$ Very Much Agree

1. It would be nice to know what kinds of drugs

people use.

$\begin{array}{lllll}\text { D } & \text { d } & \text { u } & \text { a } & \text { A } \\ \text { D } & \text { d } & \text { u } & \text { a } & \text { A } \\ \text { D } & \text { d } & \text { u } & \text { a } & \text { A } \\ \text { D } & \text { d } & \text { u } & \text { a } & \text { A }\end{array}$

can be healthy experimentation.

5. It is normal to be curious about the meaning of different drug-related terms.

$\mathrm{D}$

D

d

$\begin{array}{lllll}\text { D } & \text { d } & \text { u } & \text { a } & \text { A } \\ \text { D } & \text { d } & \text { u } & \text { a } & \text { A }\end{array}$

7. There are no benefits to using marijuana.

8. It's OK to try marijuana if you know you won't get caught.

9. It might be interesting to try marijuana.

$\begin{array}{lllll}D & d & \text { u } & \text { a } & \text { A }\end{array}$

10. It would be nice to know what kinds of people use drugs.

11. Marijuana use is associated with a weak will.

D d

D d

A

12. Hearing people use unfamiliar drug-related words can make one curious to know what those words mean.

$\mathrm{D}$

13. It would be interesting to know what using marijuana feels like.

$\mathrm{D}$

D $\quad$ d $\quad$ u $\quad$ a $\quad$ A

14. It is normal for a college student to be curious about what drugs do.

$\mathrm{D}$

d

D

d

u

a

A

16. People often wonder what kinds of drugs are available.

$\begin{array}{lllll}\text { D } & \text { d } & \text { u } & \text { a } & \text { A } \\ \text { D } & \text { d } & \text { u } & \text { a } & \text { A }\end{array}$

18. People often wonder why drugs are such a problem.

19. Using marijuana might be fun.

$\begin{array}{lllll}\text { D } & \text { d } & \text { u } & \text { a } & \text { A } \\ \text { D } & \text { d } & \text { u } & \text { a } & \text { A }\end{array}$


20. It is normal to want to know why people use drugs.
D d

$\mathrm{D}$

D d

D

d

D

$\mathrm{D}$ d

d
$\mathrm{u}$

a

a

A

22. It is normal to be curious about the effects

23. People often wonder what drug-related terms mean.

24. People often wonder what drugs do.

The first author is an assistant professor in the E.W. Scripps School of Journalism at the Scripps College of Communication, Ohio University. The second author is a professor and co-director of the Media Effects Research Laboratory in the Media Studies Department at the College of Communications, Pennsylvania State University. 